ment of the Pall HME filter. Anesth Analg 1991; 72: 651-5.

3 Wille B. Hygiene measures for anesthesia and ventilator equipment. Krankenhaus-Hygiene und Infektionsverhutung 1989; 11: 17-21.

4 Holton J, Webb $A R$. An evaluation of the microbial retention performance of three ventilator-circuit filters. Intensive Care Med 1994; 20: 233-7.

5 Mebius $C$. Heat and moisture exchangers with bacterial filters: a laboratory evaluation. Acta Anaesthesiol Scand 1992; 36: 572-76.

6 Hedley RM, Allt-Graham J. A comparison of the filtration properties of heat and moisture exchangers. Anaesthesia 1992; 47: 414-20.

7 Färber WU, Wille B. The examination of the suitability of non-hydrophobic ventilation filters as a hygienic measure. Krankenhaus-Hygiene und Infektionsverhutung 1993; 15: 116-22.

8 Snowdon SL. Hygiene standards for breathing systems? (Editorial). Br J Anaesth 1994; 72: 143-4.

\section{Management of autonomic dysfunction in severe tetanus: the use of fentanyl}

To the Editor:

Cardiovascular instability accompanying severe tetanus secondary to sympathetic overactivity and raised catecholamine concentrations, is associated with a mortality of over $50 \%{ }^{1}$ This report describes the use of fentanyl in severe tetanus after failure of established therapeutic modalities (heavy sedation, neuromuscular blockade and ventilation).

A 70-yr-old man was admitted to the ICU for tetanus which occurred seven days after minor wounds. On admission, he was conscious but had marked trismus. He was given sedation as a midazolam infusion at 5 $\mathrm{mg} \cdot \mathrm{hr}^{-1}$. Twenty-four hours after admission, he had markedly worsened with the appearance of dysphagia, severe and frequent spasms, which were not controlled with increased sedation (midazolam $10 \mathrm{mg} \cdot \mathrm{hr}^{-1}$ ) and were associated with high systolic blood pressure. A tracheostomy was performed, and thereafter ventilation continued with increased sedation. Despite $60 \mathrm{mg} \cdot \mathrm{hr}^{-1}$ midazolam, he continued to have spasms, and vecuronium was given $\left(7 \mathrm{mg} \cdot \mathrm{hr}^{-1}\right)$. At this point, daily samples for plasma catecholamines determination and concentration of catecholamines were collected on $24 \mathrm{hr}$ urine aliquots. On day seven, cardiovascular instability increased with tachycardia, arrhythmias and labile hypertension.
Fentanyl was started at dose of $5 \mu \mathrm{g} \cdot \mathrm{kg}^{-1}$, followed by a continuous infusion of between 4 and $6 \mathrm{mg} \cdot \mathrm{kg}^{-1} \cdot \mathrm{hr}^{-1}$. Fentanyl dramatically suppressed the cardiovascular instabilities. Cardiovascular stability was restored, and sedative and relaxants were reduced. By day 19 , all sedatives had been stopped. He was weaned from ventilation without difficulty by day 23 , and discharged on day 30 , and made a full recovery.

In this case, midazolam was inadequate to control sympathetic overactivity and cardiovascular dysfunction. In this setting, we have found fentanyl to be a good agent because myocardial contractility is not directly affected; toxicity to therapy is neither dose- nor time-dependent. Fentanyl, like morphine, blocks sympathetically mediated constriction of peripheral veins. ${ }^{2}$ It induces peripheral arterial dilatation by reflex reduction in sympathetic $\alpha$-adrenergic tone through alteration of the sympathetic efferent discharge at a central nervous system level. ${ }^{3}$ In our case, suppression of sympathetic overactivity after fentanyl infusion, was confirmed not only by the stability of blood pressure, heart rate, but also by the concomitant decrease in plasma catecholamine levels and urinary catecholamines excretion. This is a safe, inexpensive and simple treatment of autonomic nervous system dysfunction in severe tetanus.

Ayad Victor Moughabghab MD

Pascale Lefilliatre MD

Ali Fenides MD

Francois Provot MD

Service de Reanimation

Centre Hospitalier General de Valenciennes

F-59300 Valenciennes, France

\section{REFERENCES}

1 Trujillo $M H$, Castillo $A$, Espana A, Zerpa $R$. Impact of intensive care management on the prognosis of tetanus. Analysis of 641 cases. Chest 1987; 92: 63-5.

2 Ward JM, McGrath RL, Weil JV. Effects of morphine on the peripheral vascular response to sympathic stimulation. Am J Cardiol 1972; 29: 659-62.

3 Zelis R, Mansour EJ, Capone EJ. The cardiovascular effects of morphine. The peripheral capacitance and resistance vessels in human subjects. J Clin Invest 1974; 54: 1247-51. 